\title{
Risky business? Pharmaceutical industry sponsorship of health consumer groups
}

\section{Lisa A Bero (iD \\ Professor, Schools of Medicine and Public Health, University of Colorado, USA \\ Lisa Parker (D) \\ Honorary lecturer, Charles Perkins Centre, School of Pharmacy, Faculty of Medicine and Health, University of Sydney}

\section{Keywords}

conflict of interest, consumer organisations, medical education, pharmaceutical industry

Aust Prescr 2021:44:74-6 https://doi.org/10.18773/ austprescr.2021.017
Health consumer organisations can include groups specific to a particular condition, such as the Heart Foundation, and health system advocacy groups, such as the Consumers Health Forum of Australia. They play an important role in health care in Australia. Consumer organisations raise awareness about diseases and treatments, fund or conduct research on particular topics, and engage in advocacy for regulatory and legislative reforms that benefit consumers. These groups also educate and provide support to people living with a health condition and gain media attention for consumer issues.

Pharmaceutical industry sponsorship of health consumer groups is common. Since 2013, Medicines Australia has publicly reported the amount of money that member pharmaceutical companies provide to consumer organisations. From 2013 to 2016, companies provided a total of $\$ 34,507,810$ to 230 Australian health consumer organisations. However, nearly half of these organisations made no mention of industry sponsorship on their websites and fewer than one in five had policies governing sponsorship.'

In a US survey of 245 health consumer groups, two-thirds reported pharmaceutical industry sponsorship with about 10\% taking over $\$ 1$ million each. ${ }^{2}$ Ties may not be only financial - another US study found that $36 \%$ of 104 consumer groups had industry executives on their governing boards. ${ }^{3}$

Health consumer groups may derive important benefits from relationships with pharmaceutical companies. ${ }^{4}$ Financial support enables groups to cover administration costs and pursue activities such as education, research funding and advocacy. In-kind support from companies may help groups to grow their organisation.

Health consumer groups are confident that they are able to withstand influence from their pharmaceutical company sponsors. ${ }^{5}$ However, this same level of confidence is seen in other health sectors that receive pharmaceutical industry funding and evidence shows that this confidence is often misplaced. For example, even small gifts from pharmaceutical companies influence health professionals' behaviour, despite them strongly believing that they are not influenced by pharmaceutical company money. ${ }^{6}$

Ties between pharmaceutical companies and health consumer groups can be perceived as a conflict of interest. Companies with a fiduciary responsibility to shareholders to increase product sales tend to fund consumer groups representing patients with the conditions treated by their products. Health consumer groups have a primary mandate to represent the interests of members living with a specific condition. Industry ties could influence the ability of consumer groups to fully represent members' interests.?

Consumer groups have an important role in advocating for policies that can benefit patients. Condition-specific consumer groups often promote policies that enable access to treatment, for example by lobbying for a drug to be subsidised. Pharmaceutical companies may be eager to sponsor groups whose focus and advocacy is aimed at the disease and the drugs the companies make, because if those drugs become more accessible, sales will increase.

An Australian study identified that the industry prioritised payments to health consumer groups that were focused on diseases for which there were new drugs available. Indeed, most of the companies sponsoring the most heavily funded consumer groups had drugs under review for listing on the Pharmaceutical Benefits Scheme. ${ }^{8}$ Companies are particularly keen to sponsor group activities likely to lead to more sales, with the bulk of industry money going towards public involvement (communication, advocacy, campaigning, disease awareness) and policy engagement activities. Much less goes towards patient support or organisational maintenance. ${ }^{8-10}$

Many health consumer groups consider they have closely aligned interests with pharmaceutical companies, making the sponsorship relationship useful for both parties. In particular, both sectors may be interested in public access to affordable new drugs. However, there are important ways in which the interests of the two sectors may diverge, including the promotion of expensive drugs or drugs with questionable efficacy or poor adverse-effect profiles. Although their interests may appear aligned, consumer groups might be placed in a position to overemphasise the benefits and downplay the harms of their sponsors' products, ultimately putting consumers at risk. For example, a US study found that pharmaceutical industry-sponsored consumer groups that provided commentary on a proposed guideline to restrict the use of opioids for chronic, non-cancer pain were more 
likely to oppose the guideline than groups without such sponsorship." Industry-funded consumer representatives to the European Medicines Agency were more likely, than those without industry funding, to support a legislative proposal permitting some direct-to-consumer advertising of prescription medicines. ${ }^{12}$

By funding consumer groups whose views are aligned, the pharmaceutical industry may magnify consumer opinions pushing for access to drugs. This may effectively silence those who argue for non-pharmaceutical measures or express concerns about overdiagnosis and overtreatment. Pharmaceutical funders may also push consumer groups to lobby for drug subsidies. Such public lobbying can influence media coverage of new treatments, policies that affect the regulatory approval or financial coverage of medicines, and public opinion. Given the lack of transparency around pharmaceutical industry support for consumer groups, it is often difficult for members of the public to know whether consumer voices have financial links to the manufacturers of the products they support.

Consumer organisations have a mission to educate patients and the public about diseases and treatments. One advantage of pharmaceutical industry sponsorship of consumer groups could be financial support for patient 'educational' materials or events. However, these groups should be aware that, globally, pharmaceutical industry sponsorship has been linked to biases in clinical research, education and practice. ${ }^{13,14}$ An Australian study found that sponsoring pharmaceutical companies sometimes request direct access to consumers at educational events and seek to influence group communications through newsletters and conference materials. ${ }^{4}$ Internal pharmaceutical company documents have defined education as a 'marketing strategy'.15 Marketing messages tend to emphasise a medicine's benefits and provide limited information on harms ${ }^{16}$ while promoting high-cost, brand-name drugs over well-established, safer generic alternatives. ${ }^{17}$

Sponsorship of consumer groups could also allow direct marketing to patients through a back door. Direct-to-consumer advertising is illegal in Australia, but industry sponsorship could give companies direct access to patients through their attendance at industry-sponsored events or participation in industry- sponsored support groups. This access could be used to gather information for marketing or for new types of promotion, such as through social media. ${ }^{18}$

By building relationships with consumer groups, pharmaceutical companies can shift the focus from patients and health to their own corporate interests. In order to maintain the flow of industry money, consumer groups may align their priorities with those of their sponsors. The company priority of selling more medicines may not be the best for public health. Consumers need to be represented by truly independent groups that have consumer interests as their main concern.

Health consumer organisations looking for guidance on how to manage relationships with industry sponsors have limited options. The Consumers Health Forum of Australia has produced a document in conjunction with Medicines Australia, the main organisation for the pharmaceutical industry. ${ }^{19}$ Consumer organisations might also look to the industry's own Code of Conduct, which includes information on how the industry expects its member companies to behave. There is room for independent guidance to support groups that are looking for more assistance with developing and enacting sponsorship policies. We recently convened a seminar on this topic in conjunction with Health Consumers NSW and the Consumers Health Forum of Australia. The meeting report is available online. ${ }^{20}$ We encourage health professionals to investigate funding sources for health consumer groups that they mention to patients or engage with as advisors and to educate themselves about the risks such funding can create. Health professionals can then engage in open discussions with patients about what it might mean for a given consumer group to be funded by a particular company.

We strongly support the global move towards greater transparency around industry funding in the health sector, ${ }^{21}$ including for health consumer organisations..$^{22-24}$ If health consumer organisations made clear disclosures about the extent, amount and uses of pharmaceutical industry sponsorship, this would allow patients and referring health professionals to be much better informed about the impacts of industry influence. $\varangle$

Conflicts of interest: none declared

\section{REFERENCES}

1. Lau E, Fabbri A, Mintzes B. How do health consumer organisations in Australia manage pharmaceutical industry sponsorship? A cross-sectional study. Aust Health Rev 2019:43:474-80. https://doi.org/10.1071/AH17288

2. Rose SL, Highland J, Karafa MT, Joffe S. Patient advocacy organizations, industry funding, and conflicts of interest. JAMA Intern Med 2017;177:344-50. https://doi.org/10.1001/ jamainternmed.2016.8443
3. McCoy MS, Carniol M, Chockley K, Urwin JW, Emanuel EJ, Schmidt $\mathrm{H}$. Conflicts of interest for patient-advocacy organizations. N Engl J Med 2017;376:880-5. https://doi.org/ 10.1056/NEJMsr1610625

4. Parker L, Fabbri A, Grundy Q, Mintzes B, Bero L. "Asset exchange"-interactions between patient groups and pharmaceutical industry: Australian qualitative study. BMJ 2019;367:I6694. https://doi.org/10.1136/bmj.I6694 
5. Taylor J, Denegri S. Industry links with patient organisations. BMJ 2017;356:j1251. https://doi.org/10.1136/bmj.j1251

6. DeJong C, Aguilar T, Tseng CW, Lin GA, Boscardin WJ, Dudley RA. Pharmaceutical industry-sponsored meals and physician prescribing patterns for Medicare beneficiaries. JAMA Intern Med 2016;176:1114-22. https://doi.org/10.1001/ jamainternmed.2016.2765

7. Batt S. Who will support independent patient groups? BMJ 2014;349:g6306. https://doi.org/10.1136/bmj.g6306

8. Fabbri A, Swandari S, Lau E, Vitry A, Mintzes B. Pharmaceutical industry funding of health consumer groups in Australia: a cross-sectional analysis. Int J Health Serv 2019;49:273-93. https://doi.org/10.1177/0020731418823376

9. Ozieranski P, Rickard E, Mulinari S. Exposing drug industry funding of UK patient organisations. BMJ 2019;365:11806. https://doi.org/10.1136/bmj.11806

10. Mulinari S, Vilhelmsson A, Rickard E, Ozieranski P. Five years of pharmaceutical industry funding of patient organisations in Sweden: Cross-sectional study of companies, patient organisations and drugs. PLoS One 2020;15:e0235021. https://doi.org/10.1371/journal.pone.0235021

11. Lin DH, Lucas E, Murimi IB, Kolodny A, Alexander GC. Financial conflicts of interest and the Centers for Disease Control and Prevention's 2016 guideline for prescribing opioids for chronic pain. JAMA Intern Med 2017;177:427-8. https://doi.org/10.1001/jamainternmed.2016.8471

12. Perehudoff K, Alves TL. Patient and consumer organisations at the European Medicines Agency: financial disclosure and transparency. Amsterdam: Health Action International; 2010. https://research.rug.nl/en/publications/patient-andconsumer-organisations-at-the-european-medicines-agen [cited 2021 May 1]

13. Lo B, Field MJ, editors. Conflict of interest in medical research, education, and practice. Washington (DC): Institute of Medicine; 2009.

14. Lundh A, Lexchin J, Mintzes B, Schroll JB, Bero L. Industry sponsorship and research outcome. Cochrane Database Syst Rev 2017;2:MR000033. https://doi.org/10.1002/14651858.mr000033.pub3

15. Steinman MA, Bero LA, Chren MM, Landefeld CS. Narrative review: the promotion of gabapentin: an analysis of internal industry documents. Ann Intern Med 2006;145:284-93. https://doi.org/10.7326/0003-4819-145-4-200608150-00008
16. Mintzes B, Lexchin J, Sutherland JM, Beaulieu MD Wilkes MS, Durrieu G, et al. Pharmaceutical sales representatives and patient safety: a comparative prospective study of information quality in Canada, France and the United States. J Gen Intern Med 2013:28:1368-75. https://doi.org/10.1007/s11606-013-2411-7

17. Lexchin J. The relation between promotional spending on drugs and their therapeutic gain: a cohort analysis. CMAJ Open 2017;5:E724-8. https://doi.org/10.9778/ cmajo.20170089

18. Parker L, Williams J, Bero L. Ethical drug marketing criteria for the 21st century. BMJ 2018;361:k1809. https://doi.org/ 10.1136/bmj.k1809

19. Consumers Health Forum. Medicines Australia. Working together guide. 3rd ed. Canberra: Consumers Health Forum of Australia and Medicines Australia; 2015. https://chf.org.au/ node/478 [cited 2021 May 1]

20. Parker L, Brown A, Wells L, Joyner S, Mintzes B, Fabbri A, et al. Consumer-pharmaceutical industry relationships: building trust and transparency. Sydney: Health Consumers NSW; 2020. https://www.hcnsw.org.au/trust-andtransparency [cited 2021 May 1]

21. Moynihan R, Bero L, Hill S, Johansson M, Lexchin J, Macdonald $\mathrm{H}$, et al. Pathways to independence: towards producing and using trustworthy evidence. BMJ 2019;367:16576. https://doi.org/10.1136/bmj.16576

22. Fabbri A, Santos A, Mezinska S, Mulinari S, Mintzes B. Sunshine policies and murky shadows in Europe: disclosure of pharmaceutical industry payments to health professionals in nine European countries. Int J Health Policy Manag 2018;7:504-9. https://doi.org/10.15171/ijhpm.2018.20

23. European Federation of Pharmaceutical Industries and Associations (EFPIA). EFPIA code of practice on relationships between the pharmaceutical industry and patient organisations. Brussels: EFPIA; 2011. https://www.efpia.eu/media/24310/3c_efpia-code-ofpractice-on-relationships-pharmapluspt-orgs.pdf [cited 2021 May 1]

24. Ozieranski P, Rickard E, Mulinari S. Exposing drug industry funding of UK patient organisations. BMJ 2019:365:11806. https://doi.org/10.1136/bmj.l1806 